\title{
Avaliação de perdas nos sistemas públicos de abastecimento de água no Estado de Sergipe
}

\author{
Marcos Luciano Alves Barroso
}

Instituto Federal de Educação, Ciências e Tecnologia de Sergipe, Avenida Engenheiro Gentil Tavares do Mota 1166, Cirurgia 49050-250, Aracaju, Sergipe, Brasil. E-mail: marcos.barroso@ifs.edu.br

Barroso M.L.A. (2019) Avaliação de perdas nos sistemas públicos de abastecimento de água no Estado de Sergipe. Pesquisa e Ensino em Ciências Exatas e da Natureza, 3(1): 76-87.

http://dx.doi.org/10.29215/pecen.v3i1.1150

Editor acadêmico: Everton Vieira da Silva. Recebido: 26 Outubro 2018. Aceito: 22 Maio 2019. Publicado: 27 Maio 2019.

Resumo: Nos últimos anos, pouca atenção tem sido dada aos investimentos em manutenção e modernização da gestão dos sistemas públicos de abastecimento de água em muitas cidades brasileiras. No Estado de Sergipe, este fato resultou em uma série de ineficiências na oferta, dentre as quais, destacam-se a elevada perda de água, física e financeira para a concessionária do Estado em várias cidades. Assim este trabalho buscar identificar um retrato das condições do gerenciamento de perdas de água nos sistemas público de abastecimento nos seis maiores municípios do Estado de Sergipe. O fato se deve, pois, a concessionária indicar que à falta de tecnologia que garanta melhor monitoramento dos sistemas públicos de abastecimento de água das cidades que também não dispõem de equipamentos modernos para a medição real da água distribuída e consumida. De forma que o trabalho foi construído contabilizando informações e indicadores do Sistema Nacional de Informações sobre Saneamento (SNIS) que revelam a situação das cidades em Sergipe no período de 2008 a 2017. Que revelaram que os incentivos para uma manutenção mais eficiente são limitados e, em geral, a água é tratada como um bem livre, estimulando a falta de pagamento e o uso não controlado do mesmo. Essa situação gera muitos problemas para a manutenção da concessionária e prestadores de serviços, como a produção de água que, na maioria dos casos, é muito superior ao necessário, amplificando os custos de produção e proporcionando a perda de parcela significativa da produção de água na distribuição, além da perda física. Isto representa custo incorrido, sendo parte da água distribuída não cobrada, acarretando perdas de faturamento, ou seja, o consumidor consome, mas não paga, resultando em custos de produção e distribuição sem inferir receita.

Palavras chave: Consumo, distribuição, gerenciamento, Nordeste do Brasil, saneamento.

\section{Evaluation of losses from public water supply systems in the State of Sergipe}

Abstract: In recent years, little attention has been paid to investments in maintenance and modernization of the management of public water supply systems in many Brazilian cities. In the State of Sergipe, this fact has resulted in a series of inefficiencies in the supply, among which, the high loss of water, physical and financial for the state concessionaire in several cities stands out. Thus this work seeks to identify a picture of the conditions of water loss management in the public supply systems in the six largest municipalities of the State of Sergipe. The fact is therefore that the concessionaire indicates that the lack of technology that ensures better monitoring of public water supply systems in cities that also do not have modern equipment for the actual measurement of water distributed and consumed. Thus, the work was constructed accounting for information and indicators from the National Sanitation Information System (SNIS) that reveal the situation of cities in Sergipe from 2008 to 2017. They revealed that incentives for more efficient maintenance are limited and, in general, water is treated as a free good, stimulating non-payment and uncontrolled use of it. This situation creates many problems for the maintenance of the concessionaire and service providers, such as the production of water, which in most cases is much higher than necessary, amplifying production costs and providing a significant loss of water production in the physical loss. This represents cost incurred, part of the water is not charged, resulting in losses of billing, that is, the consumer consumes, but does not pay, resulting in costs of production and distribution without inferring revenue. 
Key words: Consumption, distribution, management, Northeastern Brazil, sanitation.

\section{Introdução}

O aumento de obras no saneamento básico nos municípios brasileiros, uma das áreas mais subdesenvolvidas da infraestrutura, dependerá de melhorias na gestão, em especial da situação considerada dramática das perdas de água nos sistemas públicos de abastecimento dos municípios. Um sistema de abastecimento público de água reúne o conjunto de obras, instalações e serviços, destinados a produzir e distribuir água potável a uma comunidade, em quantidade e qualidade compatíveis com as necessidades da população, para fins de consumo doméstico, serviços públicos, consumo industrial e outros usos (BRASIL 2017). Neste sentido, o sistema de abastecimento de água exige de quem administra fazer operações diárias, manutenção programada e reparos constantes.

No ano de 2017, as perdas da concessionária que gerencia os sistemas públicos de abastecimento de água no Estado de Sergipe (Nordeste do Brasil) e que administra os vazamentos, os roubos e ligações clandestinas, falta de medição ou medições incorretas no consumo de água obteve média de $36.64 \%$ no faturamento, dados do Sistema Nacional de Informações sobre o Saneamento (SNIS). Quando se analisa os índices médios de uma série histórica (2008-2017) no SNIS, considerando as seis maiores cidades, a perda no faturamento atinge $43.55 \%$. Já quanto às perdas na distribuição, na mesma série, os patamares também não são nada satisfatórios sendo $64.12 \%$ (2011) a $62.68 \%$ (2014) e com uma média histórica de $59.36 \%$ (BRASIL 2018).

Em Sergipe, a população atual é cerca de 2.216.112 habitantes com um consumo per capita de 116.34 1/hab./dia (BRASIL 2017). Se houver uma pequena redução, 10\% nas perdas no faturamento, para o Estado acrescentaria milhões à receita operacional com a água, significando investimentos a serem realizados em abastecimento de água para todo o Estado. Se a redução de perda for mais significativa (acima de 10\%) ajudaria ainda mais a concessionária a ter recurso para a expansão do atendimento em água potável para população, que tem um atendimento urbano de $80.91 \%$ (BRASIL 2017).

A água é um recurso indispensável para a sustentação da vida na Terra e para as atividades humanas, sendo a sua primeira a necessidade essencial e é para isso que se utiliza de serviços de abastecimento de água, os quais distribuem e fornecem água tratada com qualidade aceitável dentro dos padrões de potabilidade, de normas regulamentadas por lei e eficiência técnica. Para que essa qualidade seja atendida pelos executores desse serviço, é de grande importância se realizar o monitoramento da qualidade da água fornecida a população servindo como base para mecanismos de intervenção ou não para ajustar os parâmetros avaliados à legislação de controle vigente.

Para o estudo de perdas nos sistemas público de abastecimento de água um padrão, de informações e de indicadores, é imprescindível. Assim, inicialmente para estas análises tem-se as recomendações da International Water Association (IWA), que com o objetivo de padronizar o entendimento dos componentes dos usos da água em um sistema de abastecimento propôs uma matriz que representa o balanço hídrico, no qual são considerados dois tipos de perdas de água: reais e aparentes (Quadro 01).

Segundo Toneto Jr. et al. (2010), neste balanço, o volume de entrada no sistema refere-se ao volume de água produzido, o que é entregue ao sistema. Sendo o consumo autorizado, que corresponde ao volume de água medido e/ou não medido tomado por clientes registrados, para finalidades residenciais, comerciais e industriais. Neste, está incluso o volume de água exportado a outras localidades. Ainda, o consumo medido faturado, que corresponde ao volume de água registrado nos hidrômetros.

Já o consumo estimado, faturado, é composto pelo volume estimado por meio de consumos médios históricos ou volume mínimo de faturamento. A estimativa é utilizada nos casos em que os hidrômetros não estão em funcionamento regular ou que estes não existem nas 
ligações. Tem-se também o consumo medido não faturado, que refere-se ao volume de água utilizado pelas próprias concessionárias nas estações de tratamento; e o consumo estimado não faturado, que corresponde ao volume de água direcionado ao corpo de bombeiros, às áreas invadidas ou irregulares, entre outros eventuais destinos.

Quadro 1. Balanço hídrico proposto pela IWA. Fonte: Modelo IWA, adaptado da Funasa (BRASIL 2014).

\begin{tabular}{|c|c|c|c|c|}
\hline \multicolumn{5}{|c|}{ PERDA DE ÁGUA = VOLUME DE ENTRADA - CONSUMO AUTORIZADO } \\
\hline \multirow{9}{*}{$\begin{array}{l}\text { Volume de } \\
\text { entrada na } \\
\text { distribuição }\end{array}$} & \multirow{4}{*}{$\begin{array}{l}\text { Consumo } \\
\text { autorizado }\end{array}$} & \multirow{2}{*}{$\begin{array}{c}\text { Consumo } \\
\text { autorizado } \\
\text { faturado }\end{array}$} & Consumo medido faturado & \multirow{2}{*}{$\begin{array}{c}\text { Água } \\
\text { faturada }\end{array}$} \\
\hline & & & Consumo medido não faturado & \\
\hline & & \multirow{2}{*}{$\begin{array}{c}\text { Consumo } \\
\text { autorizado não } \\
\text { faturado }\end{array}$} & Consumo medido não faturado & \multirow{7}{*}{$\begin{array}{l}\text { Água não } \\
\text { convertida } \\
\text { em receita }\end{array}$} \\
\hline & & & Consumo não medido não faturado & \\
\hline & \multirow{5}{*}{$\begin{array}{l}\text { Perda de } \\
\text { água }\end{array}$} & \multirow{2}{*}{$\begin{array}{c}\text { Perdas } \\
\text { aparentes }\end{array}$} & Consumo não autorizado & \\
\hline & & & Imprecisão de medição & \\
\hline & & \multirow{3}{*}{ Perdas reais } & $\begin{array}{l}\text { Vazamento e extravasamento em } \\
\text { reservatórios }\end{array}$ & \\
\hline & & & Vazamentos em adutoras e redes & \\
\hline & & & Vazamentos em ramais & \\
\hline
\end{tabular}

Logo, baseado nestes componentes deve-se avaliar as primeiras consequências dos indicadores de perdas no faturamento e correlacionar com indicadores de perdas na distribuição, nos sistemas públicos de abastecimento em seis municípios, no Estado de Sergipe.

Portanto, este trabalho tem como objetivo identificar um retrato das condições do gerenciamento de perdas de água nos sistemas público de abastecimento nos seis maiores municípios (Aracaju, Nossa Senhora do Socorro, Itabaiana, Lagarto, Estância e São Cristóvão), no Estado de Sergipe, conforme informações dos bancos de dados do SNIS, do Ministério das Cidades, numa série histórica de 2008 a 2017. Além do mais, o presente estudo tem uma perspectiva conjunta de: avaliar o número de habitantes abastecidos com o sistema público e o volume de água produzido para os municípios; fazer um comparativo quanto aos indicadores de consumo per capita e as perdas entre os municípios; analisar os indicadores operacionais relativos aos índices de perdas nos municípios; e avaliar os dados de suficiência de caixa e receita operacional nos serviços de abastecimento nos municípios.

\section{Metodologia}

Os trabalhos iniciaram em março de 2017, na Coordenação do Curso de Tecnologia em Saneamento Ambiental do Instituto Federal de Educação, Ciências e Tecnologia de Sergipe (IFS), com a publicação no mesmo ano, dos dados do Sistema Nacional de Informações sobre o Saneamento (SNIS), do Ministério das Cidades e a escolha dos seis municípios no Estado de Sergipe. A pesquisa fundamente-se na análise documental, trabalhando com o banco de dados do SNIS que trata do diagnóstico anual de água e esgoto do período de 2008 a 2017. O método de coleta contou com a segregação dos dados, os números (índices) que tratam de informações e de indicadores das perdas e os números diretamente correlacionados. Já a análise dos dados foi a partir dos índices, das médias anuais e na série como também na confecção de tabelas e gráficos. A escolha dos municípios se deu dentre 75 , tendo em vista os seis municípios maiores em população no Estado de Sergipe, os quais representam 53.65\% do total. Assim, a pesquisa seguiu as seguintes etapas: (1) consultas bibliográficas em livros, revistas, sites e artigos; (2) consultas e download ao banco de informações e indicadores ao site do SNIS; (3) seleção e tabulação de dados dos municípios; e (4) uso de Software Excel na estatística, na elaboração dos gráficos e tabelas. 


\section{Resultados e Discussão}

\section{Conjuntura dos índices de perdas (Brasil e Sergipe)}

Inicialmente, para um entendimento concreto do significado dos índices de perdas de água em um sistema público de abastecimento e seus prejuízos para população atendida temos que fazer comparações com os indicadores de perdas de água do Brasil. Os indicadores de perdas de água do Brasil quando comparados com os padrões de países de primeiro Mundo têm um significativo nível de ineficiência na distribuição de água portável e no faturamento da mesma pelas concessionárias que administram os sistemas. Mesmo observando os esforços que vem sendo realizados no combater as perdas nos municípios, o conjunto torna-se preocupante porque a maior parte das concessionárias não mede suas perdas de água reais e aparentes de maneira consistente (ver Toneto Jr. et al. 2010). A média das perdas de faturamento no Brasil em 2016 foi de $36.24 \%$, bem acima da média dos países desenvolvidos, ou seja, mais que o dobro (15\%). Em relação à evolução das perdas entre 2008 e 2016 nos municípios sergipanos, o índice de perda de faturamento caiu de $52.07 \%$ em 2010 para $36.34 \%$ em 2016, uma diferença de 15.73 p.p. em nove anos. Caso seja mantido o ritmo atual de redução, será possível o Estado atingir a média dos países desenvolvidos até 2040.

Já o índice de perda na distribuição, na série, para o Estado de Sergipe apresenta de $59.04 \%$ (2010) a $60.83 \%$ (2014) e com uma redução significante, $48.10 \%$ (2016) e $47.7 \%$ no ano de 2017, situação pior que o índice de perda de faturamento. $O$ índice de perda na distribuição consolida a necessidade de maiores esforços e empenhos na diminuição das perdas pela concessionária.

No entanto, a situação de perdas na distribuição de água no Estado de Sergipe apresenta diversos aspectos de desenvolvimento e variações quando se compara as populações dos seis maiores municípios do Estado, operados por uma concessionária pública. Ainda se comparamos os dados médios, do ano de 2017, de Sergipe com a média nacional (38.3\%) e três estados nordestinos (Alagoas, Rio Grande do Norte e Piauí) que tem características semelhantes quanto ao número de habitantes atendido com o sistema público de abastecimento de água, tem-se nestes estados perdas na distribuição $(44.92,49.75$ e $48.12 \%)$ e no faturamento $(63.24,41.75$ e 45.29\%), respectivamente (BRASIL 2017), representando índices também bastantes elevados.

\section{Quanto à relação população atendida e o volume de água produzida}

Quando se analisa a população total atendida com sistema público de abastecimento de água destes municípios esta corresponde a 1.189.839 de habitantes, ou seja, 53.65\% em relação à população total do Estado de Sergipe. Tem-se em 2017, em Aracaju (capital do estado), o município de maior população atendida, 650.106 habitantes e, consequentemente, as maiores demandas, quanto aos volumes de água potável para esta população. Desta forma, historicamente, a população de Aracaju é quase dez vezes maior que a menor população (69.278 hab.), no município de Estância, com demandas menores de água. Já os municípios de N. S. do Socorro (181.928 hab.), Lagarto (104.099 hab.), Itabaiana (95.196 hab.) e São Cristóvão (89.232 hab.) também se mantêm nas mesmas posições históricas quando se trata do número da população e demanda de água (Tabela 1).

Conforme análise, os dados mostram que a distribuição do volume de água produzido é praticamente proporcional entre as populações dos municípios (Figura 1). Os dados demonstram que os volumes de águas produzidos para atender as demandas nos municípios variam ano a ano representando o volume anual de água disponível para consumo, compreendendo a água captada pelo prestador de serviços e a água bruta importada, tratadas nas unidades de tratamento do prestador de serviços, medido ou estimado nas saídas das ETAs. Os volumes de águas incluem também os volumes de água captada pelo prestador de serviços ou de água bruta importada, que sejam disponibilizados para consumo sem tratamento, medidos nas respectivas entradas do sistema de distribuição. 
O município de Aracaju possui uma população flutuante e a maior demanda de água que possa vir a ser estudado separadamente ou ter um tratamento diferenciado nos seus índices de perdas. Além disso, em Aracajú, o consumo de água varia ao longo ano também devido ao fluxo turístico. Os outros municípios tem um período de estiagem quase sempre presente no ano. Na Figura 1 se observa que a população de Aracaju corresponde a 55\% e o volume de água produzido corresponde a $64 \%$ do total entre os seis municípios.

Tabela 1. Dados do volume de água produzido para os seis municípios sergipanos conforme dados do SNIS. Abreviaturas: M - Município; A - Aracaju; E - Estância; I - Itabaiana; L - Lagarto; N.S. - N. S. do Socorro; SC - São Cristóvão; S Sergipe.

\begin{tabular}{|c|c|c|c|c|c|c|c|c|c|c|}
\hline $\mathbf{M}$ & 2008 & 2009 & 2010 & 2011 & 2012 & 2013 & 2014 & 2015 & 2016 & 2017 \\
\hline \multicolumn{11}{|c|}{$1.000 \mathrm{~m}^{3} /$ ano } \\
\hline $\mathbf{E}$ & 5.294 .48 & 548.38 & 92.87 & 298.00 & 355.00 & 411.16 & 503.00 & 569.40 & 377.75 & 338.65 \\
\hline I & 5.655 .00 & 6.376 .47 & 4.699 .05 & 5.668 .00 & 5.656 .00 & 6.020 .07 & 6.152 .00 & 7.064 .00 & 7.204 .15 & 7.020 .79 \\
\hline N.S. & 11.798 .00 & 14.300 .66 & 13.544 .57 & 15.045 .00 & 15.390 .00 & 15.178 .20 & 15.790 .00 & 13.099 .62 & 12.262 .50 & 11.534 .81 \\
\hline $\mathrm{SC}$ & 4.116 .00 & 4.047 .32 & 6.473 .86 & 4.107 .00 & 5.173 .00 & 5.951 .27 & 6.170 .00 & 4.830 .90 & 4.704 .97 & 4.519 .81 \\
\hline $\mathbf{S}$ & 95.561 .48 & 101.938 .79 & 107.383 .67 & 117.592 .00 & 119.000 .00 & 117.949 .43 & 121.336 .00 & 93.087 .88 & 84.072 .77 & 80.823 .61 \\
\hline
\end{tabular}
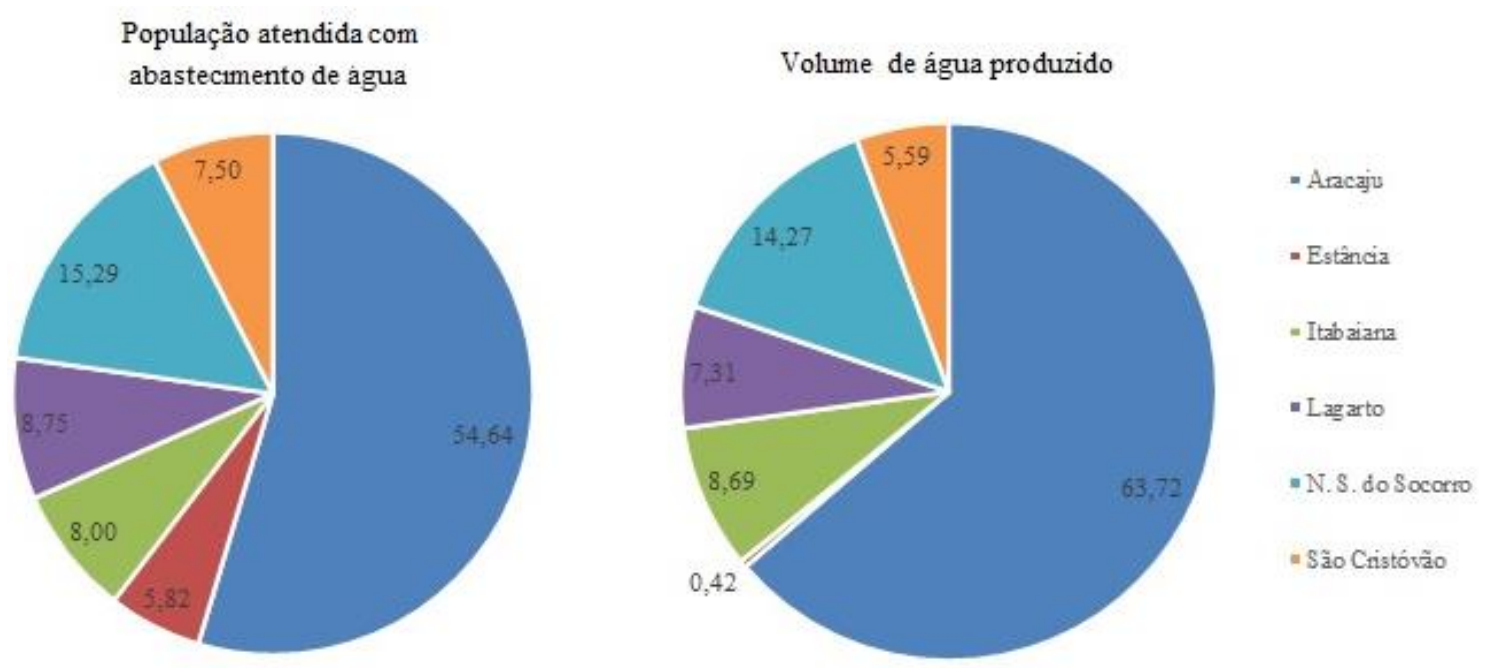

Figura 1. População atendida com abastecimento e o volume de água produzido nos municípios (SNIS 2017).

\section{Quanto aos índices médios de perdas no faturamento}

Na avaliação dos dados da Tabela 2 é possível observar as oscilações dos índices de perdas no faturamento, nos seis municípios, no Estado de Sergipe, que são notáveis. Por exemplo, enquanto o município de Aracaju apresenta índice igual a 20.93\% (2017), o município de São Cristóvão apresenta índice de 71.65\% (2010).

Os altos índices mostram que os níveis de perdas nos sistemas de abastecimento nos municípios variaram de 53.90\% (Aracaju - 2011), 79.13\% (Estância - 2014), 46.87\% (Itabaiana 2009), 62.1\% (Lagarto - 2011), 63.70\% (N. S. do Socorro - 2011) a 71.65\% (São Cristóvão - 2016).

No conjunto das amostras, apenas $9.11 \%$ dos dados estão com índices abaixo de $30 \%$ e quando comparados os índices entre os municípios, eles estão correlacionados à abrangência e a qualidade dos serviços da concessionária. Nestes dez anos de levantamento, conforme demonstram os dados da Tabela 2, três cidades (Estância, N. S. do Socorro e São Cristóvão) exibiram um desempenho pior, com índices maiores que 57\%, e maiores que o da média 
estadual 48.93\%, com índices de 66.6, 58.91 e 57.17\%, respectivamente. Estes índices também são maiores que a média nacional (33.24\%).

Tabela 2. Índices médios de perdas no faturamento em municípios sergipanos conforme dados do SNIS.

\begin{tabular}{|c|c|c|c|c|c|c|c|c|c|c|c|}
\hline \multirow{2}{*}{ Município } & 2008 & 2009 & 2010 & 2011 & 2012 & 2013 & 2014 & 2015 & 2016 & 2017 & \multirow{2}{*}{ Média } \\
\hline & \multicolumn{10}{|c|}{$\%$} & \\
\hline Aracaju & 46.40 & 49.85 & 51.25 & 53.9 & 52.34 & 48.37 & 51.79 & 32.15 & 22.60 & 20.93 & 42.96 \\
\hline Estância & 60.60 & 72.73 & 19.65 & 68.8 & 72.11 & 75.92 & 79.13 & 78.28 & 72.15 & 73.25 & 67.26 \\
\hline Itabaiana & 43.00 & 46.87 & 25.01 & 33.3 & 27.30 & 31.70 & 25.98 & 33.62 & 34.89 & 32.79 & 33.45 \\
\hline Lagarto & 42.30 & 54.45 & 50.22 & 62.1 & 46.74 & 42.73 & 43.94 & 38.22 & 40.08 & 40.50 & 46.13 \\
\hline N. S. do Socorro & 57.00 & 63.09 & 61.37 & 63.7 & 62.70 & 62.18 & 60.52 & 51.37 & 48.25 & 46.53 & $\mathbf{5 7 . 6 7}$ \\
\hline São Cristóvão & 40.60 & 53.69 & 71.65 & 58.5 & 62.21 & 67.15 & 62.61 & 50.04 & 48.10 & 47.31 & 56.19 \\
\hline Sergipe & 48.32 & 56.78 & 46.53 & 56.72 & 53.90 & 54.68 & 54.00 & 47.28 & 44.35 & 43.55 & 51.39 \\
\hline
\end{tabular}

Neste sentido, estes municípios precisam de maior atenção na redução de perdas no faturamento, pois necessitaram de recursos financeiros para a manutenção, operação e ampliação do sistema. Há de convir que índices altos nas perdas no faturamento possam estar ligados diretamente com a eficiência operacional nos sistemas. Em contrapartida, o município de Aracaju, chegou a ter índice no faturamento de $20.93 \%$ (2017) e o município de Itabaiana de $25.01 \%$ (2010), ambos reconhecidos como resultados de ótima qualidade no ano. Tais dados indicam que houve ações por parte da concessionária para uma efetiva cobrança. Itabaiana, na média, ocupa a primeira posição em termos de bom desempenho, com níveis de perdas de média em $33.45 \%$ da série. Tais índices, quando mantidos, resultam em lucros e, consequentemente, em investimentos na ampliação do sistema no município.

\section{Quanto aos índices médios de perdas na distribuição}

Em relação aos índices médios de perdas na distribuição (Tabela 3), os quais medem as perdas em termos de volume de água consumido (medido ou estimado), a média para o Estado foi de $57.28 \%$ (2008-2016), valor percentualmente acima do índice de perdas no faturamento no mesmo período $(48.93 \%)$.

Ainda, na Tabela 3, tem-se que apenas o município de Itabaiana com $46.30 \%$ na média, tem um desempenho com valor inferior à média estadual (57.28\%), que é um resultado fora de qualquer padrão aceitável, em termos de índice de perda na distribuição. Situação que seguem para as demais cidades, com índices de 58.50\% (Aracaju - 2011), 84.89\% (Estância - 2014), $55.45 \%$ (Itabaiana - 2009), 69.00\% (Lagarto - 2011), 69.50\% (N. S. do Socorro - 2011) a $76.18 \%$ (São Cristóvão - 2010). A Tabela 3 demonstram elevados índices médios de perdas na distribuição. A concessionária no período não investiu no combater as perdas de monitorando das redes nos municípios.

Tabela 3. Índices médios de perdas na distribuição nos seis municípios sergipanos conforme dados do SNIS.

\begin{tabular}{|c|c|c|c|c|c|c|c|c|c|c|c|}
\hline \multirow{2}{*}{ Município } & 2008 & 2009 & 2010 & 2011 & 2012 & 2013 & 2014 & 2015 & 2016 & 2017 & \multirow{2}{*}{ Média } \\
\hline & \multicolumn{10}{|c|}{$\%$} & \\
\hline Aracaju & 51.33 & 54.81 & 56.18 & 58.50 & 57.58 & 54.77 & 57.88 & 41.54 & 33.45 & 33.29 & 49.93 \\
\hline Estância & 61.23 & 77.64 & 39.65 & 76.20 & 78.87 & 81.76 & 84.89 & 83.07 & 80.59 & 80.48 & 74.44 \\
\hline Itabaiana & 51.93 & 55.45 & 37.92 & 45.80 & 41.81 & 45.33 & 40.80 & 47.15 & 48.48 & 48.37 & 46.30 \\
\hline Lagarto & 52.31 & 62.01 & 58.93 & 69.00 & 57.59 & 54.39 & 55.76 & 51.80 & 53.91 & 53.79 & 56.95 \\
\hline N. S. do Socorro & 63.20 & 68.45 & 67.13 & 69.50 & 68.58 & 68.14 & 67.02 & 59.93 & 58.00 & 57.88 & 64.78 \\
\hline São Cristóvão & 46.45 & 61.38 & 76.18 & 65.70 & 68.86 & 72.93 & 69.71 & 59.93 & 58.00 & 58.39 & 63.75 \\
\hline Sergipe & 54.41 & 63.29 & 56.00 & 64.12 & 62.22 & 62.89 & 62.68 & 57.24 & 55.41 & 55.37 & 59.36 \\
\hline
\end{tabular}


Resultados que acompanharam os índices médios no faturamento (Figura 2) devem servir de alerta a concessionária pelo baixo desempenho apresentado ao longo dos anos e, consequentemente, precisando de um maior esforço a fim de reduzir as perdas do líquido, um recurso hídrico limitado para a região. Estas perdas financeiras derivam da água produzida, mas que não consegue ser cobrada do usuário por problemas técnicos e de ineficiência da concessionária, entre outros.

Conforme Toneto Jr. et al. (2010), as perdas financeiras são derivadas das ligações clandestinas, roubos de água, problemas e/ou falta de hidrantes e de medição, em geral, submedições e, sobretudo dos vazamentos que ocorrem por sobre pressão nas redes em horários de baixa demanda, por corrosão e/ou idade avançada das redes de distribuição, uso de materiais inadequados ou fora dos padrões técnicos e obras mal executadas.

Na Figura 2 é possível observar as médias do município de Itabaiana; a concessionária tem os menores números na relação dos índices $(33.52 \%$ de perdas no faturamento e $46.30 \%$ de perdas na distribuição), demonstrando não ser a relação mais favorável, mais indicando uma melhor situação no conjunto entre os municípios. Ao contrário, o conjunto de dados dos municípios de Estância, N. S. do Socorro e São Cristóvão indicam a pior situação e demonstram que a concessionária deve atuar o mais breve possível para reverter o quadro.

\section{Índices médios de perdas no faturamento (\%)}

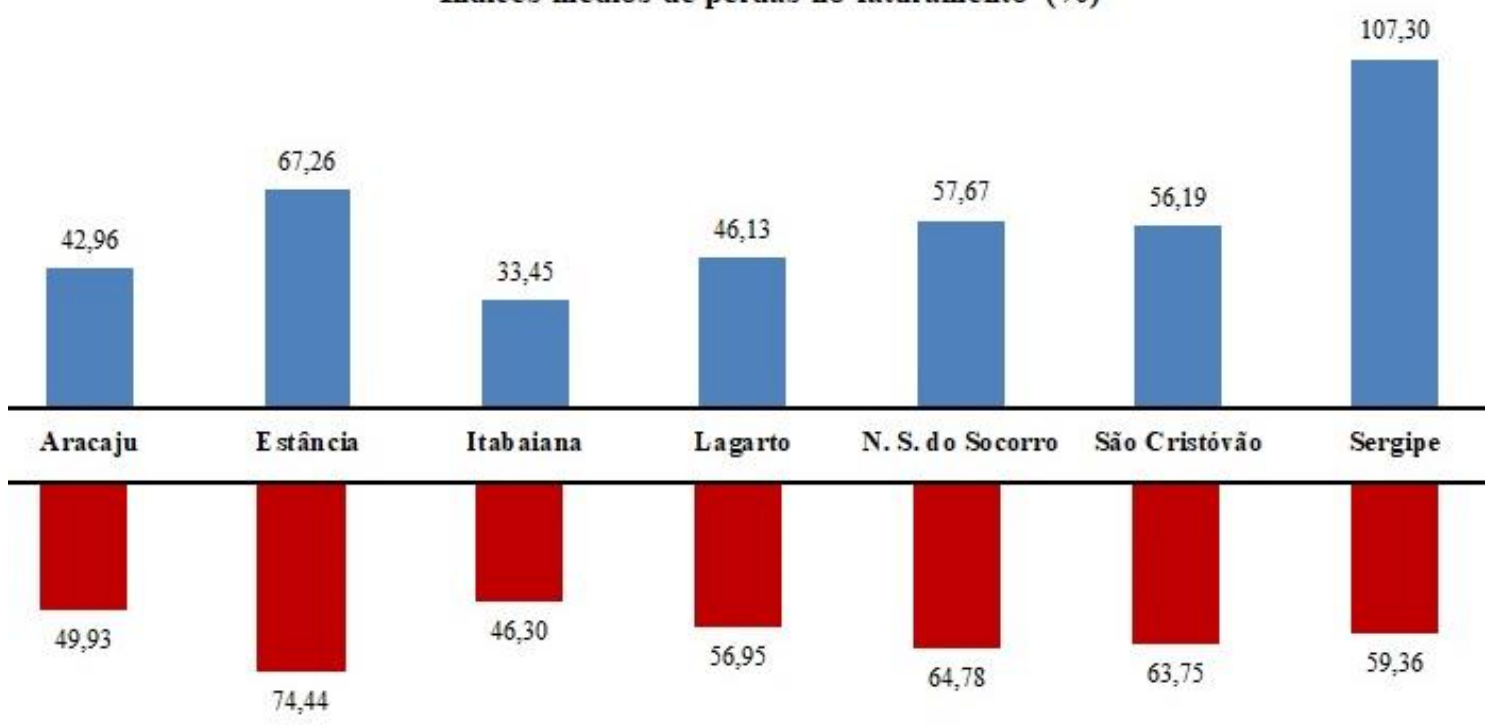

Índices médios de perdas na distribuição (\%)

Figura 2. Relação dos índices de perdas no faturamento e na distribuição em municípios sergipanos conforme dados do SNIS.

\section{Quanto aos indicadores de consumo per capita de água dos municípios}

A Tabela 4 demonstra os indicadores de consumo per capita nos municípios no período de 2008 a 2016, os quais apresentaram uma variação de 175.97 (2013) a 154.63 1/hab./dia (2016) em Aracaju, de 122.50 (2009) a 61.70 l/hab./dia (2010) em Estância, municípios com as maiores variações. Já de 100.00 (2010) a 111.87 1/hab./dia (2015) em Itabaiana, de 94.70 (2012) a 87.88 1/hab./dia (2016) em Lagarto, municípios com as menores variações. Quando analisadas as médias, apenas o município de Aracaju tem consumo médio acima do esperado (110 1/hab./dia) e se mantém ao longo da série. No entanto, valores de consumo mantidos abaixo dos recomendáveis da ONU, 110 l/hab./dia (Oliveira et al. 2015) podem vir a comprometer hábitos higiênicos e, consequentemente, afetar a qualidade de vida e da saúde da população.

Dos seis municípios apenas dois demonstraram que o consumo per capita de água aumentou no período. No entanto, não havendo aumento significativo; Itabaiana com um aumento de 8.1p.p. chegou a 111.87 1/hab./dia e N. S. do Socorro com 2.11p.p. e 105.73 1/hab./dia. 
Os aumentos podem estar ligados ao crescimento da economia dos municípios. Conforme Heller \& Pádua (2010), fatores como o clima, a temperatura e a renda familiar também contribuem para aumentar o consumo per capita de água em um município. Os dados da Tabela 4 ainda demonstram que os municípios Aracaju (2013) e Estância (2010) apresentam a maior diferença no consumo per capita fato que deve estar diretamente ligado a diferença no número de habitantes que existe entre as duas populações.

Tabela 4. Valores do consumo per capita de água nos seis municípios sergipanos conforme dados do SNIS.

\begin{tabular}{|c|c|c|c|c|c|c|c|c|c|c|c|}
\hline \multirow{2}{*}{ Município } & 2008 & 2009 & 2010 & 2011 & 2012 & 2013 & 2014 & 2015 & 2016 & 2017 & \multirow{2}{*}{ Média } \\
\hline & \multicolumn{10}{|c|}{ 1/hab./dia } & \\
\hline Aracaju & 163.40 & 163.10 & 167.30 & 173.30 & 173.20 & 175.97 & 162.32 & 158.55 & 154.63 & 146.57 & 163.83 \\
\hline Estância & 105.80 & 122.50 & 61.70 & 85.60 & 88.60 & 84.84 & 82.41 & 107.10 & 81.81 & 90.94 & 91.13 \\
\hline Itabaiana & 101.20 & 101.50 & 100.10 & 101.30 & 105.70 & 102.74 & 110.57 & 111.87 & 110.01 & 106.50 & 105.15 \\
\hline Lagarto & 93.90 & 94.10 & 90.10 & 92.00 & 94.70 & 90.77 & 92.73 & 90.44 & 87.88 & 88.73 & 91.54 \\
\hline N. S. do Socorro & 97.90 & 98.40 & 95.50 & 99.20 & 105.70 & 102.64 & 105.73 & 103.75 & 100.02 & 93.88 & 100.27 \\
\hline São Cristóvão & 98.50 & 66.80 & 95.30 & 92.50 & 96.40 & 87.33 & 96.87 & 95.87 & 95.25 & 93.88 & 91.87 \\
\hline Sergipe & 110.12 & 107.73 & 101.67 & 107.32 & 110.72 & 107.38 & 108.44 & 111.26 & 104.93 & 103.42 & 107.30 \\
\hline
\end{tabular}

Já na Figura 3 quando comparamos os dados médios do consumo per capita e os índices médios de perda na distribuição tem-se que não há uma relação direta, consumo e perdas, ou seja, existem municípios que possuem alto consumo (> 100 l/hab./dia) e um alto índice de perda (> 45\%), como é o caso de Aracaju, Itabaiana e N. S. do Socorro. Neles estão as maiores populações e demandas de água provocando assim grandes perdas. Estância e São Cristóvão estão entre os municípios com baixo consumo (< 100 l/hab./dia) e alto índice de perda (>65\%) na distribuição. Os altos índices de perdas estão relacionados com as condições de operação e manutenção das redes de distribuição. Considerando que as populações dos seis municípios passem a consumir mais água, ou seja, consumo superior a 110 l/hab./dia que é o valor recomendado pela Organização das Nações Unidas (ONU) e os índices de perdas continuariam acima da média (45\%). Segundo o que preconiza Oliveira et al. (2015), os níveis de adequação da disponibilidade hídrica para estes municípios devem ser avaliados observando as necessidades de haver abastecimento satisfatório (situação adequada), requerer ampliação do sistema (situação intermediária) e novo manancial (situação inadequada). Nestes casos, os dois últimos grupos representam municípios nos quais devem ser feitos investimentos para combater as perdas e para atender as demandas urbanas por água nos próximos anos.

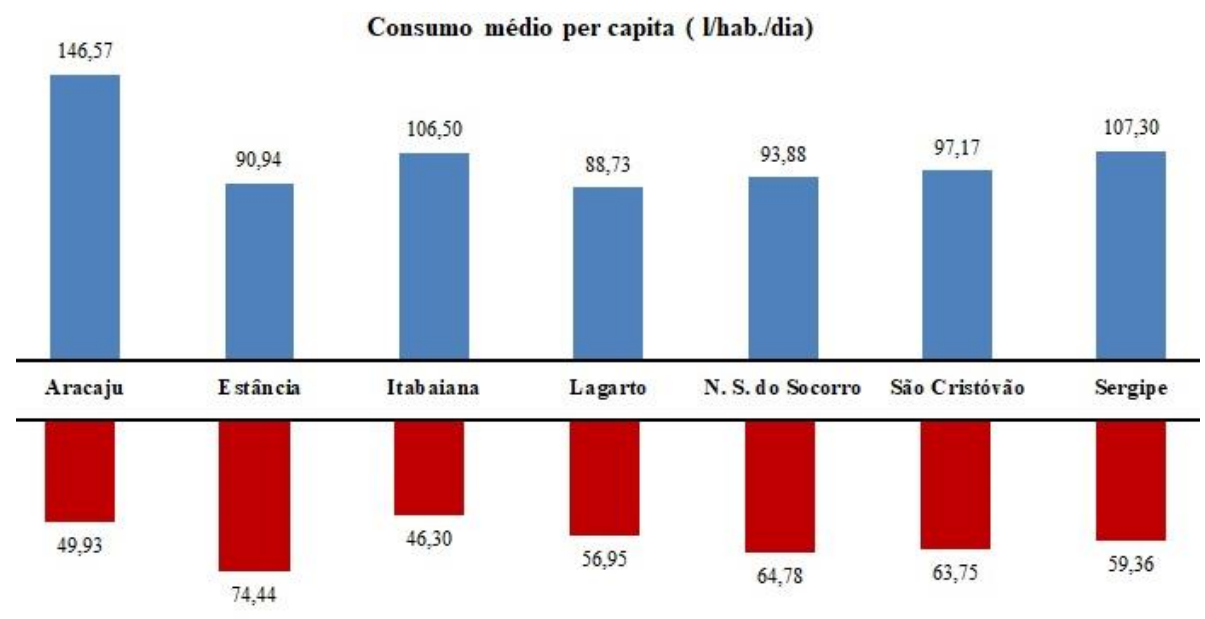

Índices médios de perdas na distribuição (\%)

Figura 3. Relação dos consumos médios per capita e índices médios de perdas na distribuição em municípios sergipanos conforme dados do SNIS. 


\section{Quanto aos índices de suficiência de caixa dos municípios}

A Tabela 5 demonstra a evolução dos índices de suficiência de caixa que os municípios tiveram de 2008 a 2017. Em Aracaju, maior município, a variação dos índices manteve-se, em oito anos da série, com os índices de suficiência de caixa menores que $100 \%$. Ao contrário dos municípios de Itabaiana e Lagarto que demonstraram excelentes desempenhos dos índices de suficiência de caixa, maiores que $100 \%$, ao longo da série. Contudo, as suficiências de caixa abaixo de $100 \%$ significam que os dividendos dos serviços não são suficientes para cobrir os gastos com estes mesmos serviços; se mantido estes percentuais ao longo dos anos, isto pode comprometer investimentos no município no combate as perdas.

Tabela 5. Evolução dos índices de suficiência de caixa dos municípios sergipanos conforme dados do SNIS (2008-2017).

\begin{tabular}{|c|c|c|c|c|c|c|c|c|c|c|c|}
\hline \multirow{2}{*}{ Município } & 2008 & 2009 & 2010 & 2011 & 2012 & 2013 & 2014 & 2015 & 2016 & 2017 & \multirow{2}{*}{ Média } \\
\hline & \multicolumn{10}{|c|}{$\%$} & \\
\hline Aracaju & 105.59 & 94.50 & 75.77 & 85.80 & 86.65 & 91.73 & 83.30 & 93.07 & 87.25 & 96.27 & 89.99 \\
\hline Estância & 99.58 & 116.37 & 100.51 & 102.30 & 111.06 & 97.95 & 82.35 & 101.99 & 99.99 & 95.51 & 100.76 \\
\hline Itabaiana & 149.07 & 155.30 & 169.21 & 175.10 & 190.30 & 194.93 & 183.81 & 145.17 & 144.22 & 133.73 & 164.08 \\
\hline Lagarto & 119.73 & 113.41 & 140.58 & 155.10 & 163.53 & 180.31 & 149.65 & 111.49 & 116.12 & 127.41 & 137.73 \\
\hline $\begin{array}{l}\text { N. S. do } \\
\text { Socorro }\end{array}$ & 50.01 & 52.37 & 50.03 & 54.60 & 54.48 & 58.86 & 63.13 & 73.77 & 68.92 & 76.24 & 60.24 \\
\hline $\begin{array}{l}\text { São } \\
\text { Cristóvão }\end{array}$ & 63.00 & 52.92 & 49.97 & 49.80 & 48.91 & 53.80 & 56.49 & 64.04 & 64.54 & 70.13 & 57.36 \\
\hline Sergipe & 97.83 & 97.48 & 97.68 & 103.78 & 109.16 & 112.93 & 103.12 & 98.26 & 96.84 & 99.88 & 101.70 \\
\hline
\end{tabular}

A Figura 4 demonstra os índices médios de suficiência de caixa dos municípios de 2008 a 2017 associados aos índices médios de perdas no faturamento. Três municípios aparecem com um bom desempenho, acima de 100\%: Estância, Itabaiana e Lagarto, $101.34 \%, 167.46 \%$ e $138.88 \%$, respectivamente. No entanto, apenas Itabaiana surge com o melhor resultado com perdas menores no faturamento $(33.45 \%)$ sinalizando uma situação para ser seguida pelos demais municípios.

Índice médios de perdas no faturamento (\%)

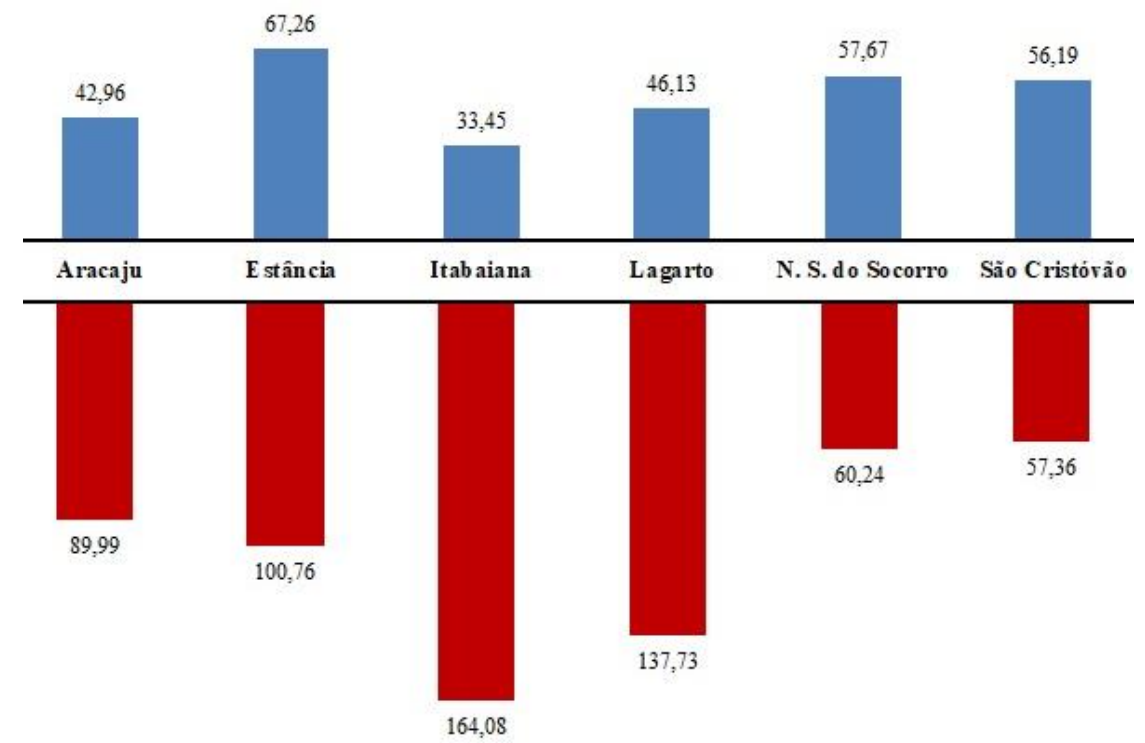

Índices médios de suficiência de caixa (\%)

Figura 4. Relação dos índices médios de perdas no faturamento e índices médios de suficiência de caixa dos municípios conforme dados do SNIS. 
Os dados mostram também que $43.33 \%$ da amostra tem índices de suficiência de caixa superiores a $100 \%$. Portanto, há um grande potencial de redução de perdas de água nesses municípios, e, consequentemente, de aumento da disponibilidade hídrica para os usuários e de ganhos financeiros para os operadores.

Os dados dos seis municípios, de elevados índices de perdas de faturamento, implicam na não obtenção, em média, da arrecadação total nem para cobrir as suas despesas correntes. Isto é, reafirmando com índices de suficiência de caixa menores que $100 \%$, as somas das receitas operacionais não cobrem a soma das despesas totais com os mesmos serviços. Há de ressaltar, em particular, que maiores índices de suficiência de caixa podem não refletir eficiência da concessionária no município, mais sim maior capacidade e eficácia na cobrança ou mesmo tarifas mais altas.

\section{Quanto às informações das receitas operacionais direta de água nos municípios}

As concessionárias têm como receita operacional direta de água o valor faturado anual decorrentes da prestação do serviço de abastecimento de água, resultante exclusivamente da aplicação de tarifas e/ou taxas, excluídos os valores decorrentes da venda de água exportada no atacado (SNIS 2017). Na Tabela 6 é possível ver a evolução da receita operacional direta de água (100.000 reais por ano) que os municípios obtiveram com as cobranças de tarifas e taxas ao longo de 2008 a 2017.

Perante a complexidade do tema perdas, com todos indicadores analisados, não é possível dizer as origens. Os elevados índices de perdas têm impacto sobre a despesa total dos serviços nos municípios (Covas \& Ramos 2007).

Os dados da Tabela 6 mostram ainda que $90 \%$ da amostra a receita operacional direta de água tem crescimento ao longo dos anos, e assim existindo grande potencial de redução de perdas de água na distribuição dos municípios; porém, não implicam na suficiência de caixa e sim depende da capacidade de cobrança. Ainda, as perdas somente serão reduzidas quando houver no sistema, eficiência do uso dos recursos hídricos e quando houver eficiência na gestão de cobrança. No entanto, observa-se que sendo a concessionária, empresa pública, estas receitas em conjunto dos seis maiores municípios possam vir para atender também outros municípios menores deficitários no Estado.

Tabela 6. Evolução da receita operacional direta de água em municípios sergipanos conforme dados do SNIS.

\begin{tabular}{|c|c|c|c|c|c|c|c|c|c|c|}
\hline \multirow{2}{*}{ Município } & 2008 & 2009 & 2010 & 2011 & 2012 & 2013 & 2014 & 2015 & 2016 & 2017 \\
\hline & \multicolumn{10}{|c|}{$100.000 \times \mathrm{R} \$$ /ano } \\
\hline Aracaju & 994.42 & 1.126 .87 & 1.276 .13 & 1.415 .87 & 1.628 .35 & 1.676 .47 & 1.660 .74 & 1.517 .06 & 1.874 .72 & 2.102 .50 \\
\hline Estância & 32.90 & 3.51 & 1.67 & 2.60 & 2.90 & 2.93 & 3.30 & 3.81 & 3.90 & 4.28 \\
\hline Itabaiana & 69.67 & 80.28 & 87.58 & 94.91 & 116.36 & 123.91 & 140.89 & 163.08 & 189.56 & 203.22 \\
\hline Lagarto & 57.55 & 64.77 & 66.82 & 70.66 & 83.77 & 88.52 & 95.82 & 118.31 & 136.50 & 147.10 \\
\hline $\begin{array}{l}\text { N. S. do } \\
\text { Socorro }\end{array}$ & 110.22 & 125.24 & 127.39 & 134.61 & 170.70 & 188.26 & 205.93 & 235.84 & 274.33 & 272.46 \\
\hline $\begin{array}{c}\text { São } \\
\text { Cristóvão }\end{array}$ & 45.70 & 18.19 & 40.49 & 41.07 & 53.49 & 67.72 & 80.28 & 85.76 & 93.75 & 99.04 \\
\hline
\end{tabular}

\section{Quanto aos índices de cobertura de água}

A Tabela 7 demonstra uma evolução do percentual da população urbana que passaram a receber água do sistema público de abastecimento. Nela, observa-se apenas dois municípios (Aracaju e Itabaiana) que tiveram percentuais aumentados no período, diferente dos demais municípios, os quais apresentaram um retrocesso quando analisados os anos de 2008 e 2017. Em particular, o município de Estância possui dados em processo de revisão.

De modo geral, no período de dez anos, as relações das médias dos índices de atendimento de água com os índices de perdas no faturamento e distribuição nos seis municípios 
são inversas. Assim pode ser observado que os índices médios de atendimento são altos com crescimento superior a $70 \%$. No entanto, os índices de perdas (faturamento e distribuição) apresentam valores médios no decaimento, ainda que altos, $>51 \%$ e $>59 \%$, respectivamente.

Tabela 7. Evolução dos índices de atendimento urbano com água em municípios sergipanos conforme dados do SNIS.

\begin{tabular}{|c|c|c|c|c|c|c|c|c|c|c|c|}
\hline \multirow{2}{*}{ Município } & 2008 & 2009 & 2010 & 2011 & 2012 & 2013 & 2014 & 2015 & 2016 & 2017 & \multirow{2}{*}{ Média } \\
\hline & \multicolumn{10}{|c|}{$\%$} & \\
\hline Aracaju & 98.80 & 98.87 & 98.96 & 91.1 & 99.14 & 99.17 & 99.19 & 99.21 & 99.29 & 99.60 & 98.33 \\
\hline Estância & 90.50 & 4.31 & 3.46 & 3.95 & 3.57 & 3.73 & 3.73 & 3.50 & 3.66 & 2.96 & 12.34 \\
\hline Itabaiana & 91.90 & 90.15 & 93.77 & 96.4 & 97.24 & 97.38 & 98.16 & 98.14 & 98.57 & 98.18 & 95.99 \\
\hline Lagarto & 91.60 & 76.31 & 74.80 & 77.4 & 80.00 & 80.51 & 84.00 & 83.40 & 81.48 & 81.12 & 81.06 \\
\hline $\begin{array}{l}\text { N. S. do } \\
\text { Socorro }\end{array}$ & 82.50 & 80.78 & 80.63 & 76.2 & 76.59 & 76.31 & 79.00 & 78.37 & 79.69 & 77.23 & 78.73 \\
\hline $\begin{array}{l}\text { São } \\
\text { Cristóvão }\end{array}$ & 100.00 & 53.56 & 51.55 & 53.4 & 60.33 & 61.70 & 62.36 & 65.68 & 64.18 & 55.47 & 62.82 \\
\hline Sergipe & 92.55 & 67.33 & 67.20 & 66.41 & 69.48 & 69.80 & 71.07 & 71.38 & 71.15 & 69.09 & 71.55 \\
\hline
\end{tabular}

\section{Conclusões}

Após avaliação das informações e indicadores consultados na base de dados do SNIS, de 2008 a 2017, na qual foi realizada uma depuração para identificar uma primeira imagem das condições do gerenciamento de perdas de água nos sistemas público de abastecimento nos seis maiores municípios no Estado de Sergipe, que proporcionou analisar a eficiência da concessionária, conclui-se que as comparações dos diferentes índices entre os municípios envolvidos nem sempre podem ser realizadas, pois as realidades dos números de habitantes locais não permitem.

De maneira geral, a concessionária tem o mesmo padrão de serviço aos consumidores nos seis municípios sendo Itabaiana o de melhor resultado. No entanto, quando se trata de perdas de água nos sistemas, os números são considerados altos comparados aos índices nacionais, de forma que, há necessidade de investimentos financeiros, tecnológicos e humanos no combate as perdas. As perdas de água representam um dos maiores desafios e dificuldades para a expansão das redes de distribuição de água. As perdas financeiras nos seis municípios com a água produzida e não faturada faz com que a concessionária perca recursos financeiros fundamentais também para a expansão do esgotamento sanitário. Logo, os resultados mostram que o nível de combate às perdas tem sido muito desigual nos municípios fazendo com que tenham diferenças entre os índices de perdas.

Por fim, entre as causas do nível atual de perdas nos sistemas, nos municípios, faz-se necessário uma análise conjunta da concessionária, primariamente, pela falta de investimento em manutenção e reabilitação das redes, da necessidade de adoção das tecnologias requeridas para o monitoramento das redes e da produção de água, de incentivos para melhorias na gestão, e de uma definição de preços que não refletem o grau de escassez do recurso hídrico.

\section{Agradecimentos}

Aos avaliadores pela revisão crítica do manuscrito.

\section{Referências}

BRASIL (2014) Ministério da Saúde. Fundação Nacional de Saúde. Redução de perdas em sistemas de abastecimento de água / Ministério da Saúde, Fundação Nacional de Saúde. $2^{\circ}$ edição. Brasília: Funasa. 172 p. 
BRASIL (2017) Ministério das Cidades. Secretaria Nacional de Saneamento Ambiental - SNSA. Sistema Nacional de Informações sobre Saneamento SNIS: "Glossários de informações e indicadores de água e esgotos, resíduos sólidos e águas pluviais”. Disponível em: http://snis.gov.br/glossarios (Acessado em 15/03/2017).

BRASIL (2017) Ministério das Cidades. Secretaria Nacional de Saneamento Ambiental - SNSA. Sistema Nacional de Informações sobre Saneamento SNIS: Série Histórica. Disponível em: http://www.snis.gov.br/aplicacao-web-serie-historica (Acessado em 26/03/2017).

BRASIL (2018) Ministério das Cidades. Secretaria Nacional de Saneamento Ambiental - SNSA. Sistema Nacional de Informações sobre Saneamento SNIS: Série Histórica. Disponível em: http://www.snis.gov.br/aplicacao-web-serie-historica (Acessado em 26/03/2018).

Covas D. \& Ramos H. (2007) Minimização de perdas de água em sistemas de Abastecimento (p. 47-66). In: Gomes H.P. (Ed.). Abastecimento de água: O estado da arte e técnicas avançadas. João Pessoa: UFPB/Editora Universitária. 386 p.

Heller L. \& Pádua V. L. (2010) Abastecimento de água para consumo humano. $2^{\circ}$ edição. Belo Horizonte: UFMG. 1290 p.

Oliveira G., Scazufca P., Marcato F.S., Orjuela G., Arouca L.F.A.F. \& Aguiar S.S. (2015) Perdas de Água: Desafios ao Avanço do Saneamento Básico e à Escassez Hídrica. São Paulo: Trata Brasil. 112 p. Disponível em: http://tratabrasil.org.br/datafiles/estudos/perdas-de-agua/Relatori o-Perdas-2013.pdf (Acessado em 10/06/2017).

Toneto Jr. R., Saiani C.C.S. \& Rodrigues R.L. (2010) Perdas de água: entraves ao avanço do saneamento básico e riscos de agravamento à escassez hídrica no Brasil. Ribeirão Preto: FUNDACE. 52 p. Disponível em: http://prattein.com.br/home/images/stories/230813/Desenvol vimento_Sustentavel/estudo_perdas_gua.pdf (Acessado em 12/12/2017). 